\title{
ANALISIS LOYALITAS ANAK BUAH KAPAL (ABK) ARMADA KAPAL PINISI PT. ASWIL LAUTAN SEJATI
}

\author{
Aldila Anggun Kinanti ${ }^{1}$ \\ Departemen Logistik, PT Aswil Lautan Sejati, Gresik, \\ Indonesia, aldilakinanti@icloud.com \\ Moh. Agung Surianto ${ }^{2}$ \\ Program Studi Manajemen, Universitas Muhammadiyah Gresik, Gresik \\ Indonesia, cakagung@umg.ac.id \\ Abdurrahman Faris Indriya Himawan ${ }^{3}$ \\ Program Studi Manajemen, Universitas Muhammadiyah Gresik, Gresik \\ Indonesia, faris@umg.ac.id
}

\begin{abstract}
Background - Companies need good employees as one of the company's assets who have an important role in carrying out organizational activities. Employees who are needed are not only capable, competent and skilled, but most importantly they also have a high sense of loyalty. Loyalty is necessary so that these employees can work not only for themselves but also for the advancement of the company
\end{abstract}

Diterima : 06 April 2021

Direview : 07 April 2021

Direvisi : 10 Mei 2021

Disetujui : 24 Mei 2021

Purpose - The purpose of this research is to analyze the loyalty of the ship crew (ABK) Pinisi Ship Fleet PT. Aswil Lautan Sejati

Design/ Methodology/ Approach - Using qualitative methods with a phenomenological study model. The informants in this study were ship crew (ABK) who had worked for at least 10 years (3 people), then the ship's captain and ship owner. Data collection techniques using interviews, with data analysis techniques using data reduction, data presentation, conclusions and verification.

Conclusion - The crew members are capable and responsible for carrying out work based on their position and the relationship between the ship owner and the crew is like there is no distance. Supporting loyalty in profit-sharing compensation is the best way for ABK to feel.

Result and discussion - Based on the results of the study, the researchers concluded that the crew members are loyal to the company which is shown by their attitudes and behavior at work and towards colleagues and superiors even though there is no guarantee / insurance in doing their job.

Research Implication- be a reference in strategies to improve employee welfare, not financial aspects, but also non-financial aspects such as health and safety insurance.

Keywords : Loyalty, Ship, Crew

\begin{abstract}
ABSTRAK
Latar Belakang - Perusahaan memerlukan karyawan yang baik sebagai salah satu aset perusahaan yang memiliki peran penting dalam menjalankan kegiatan organisasi. Karyawan yang diperlukan tidak hanya yang mampu, cakap dan terampil, tetapi yang terpenting mereka juga mempunyai rasa loyalitas yang tinggi. Sikap loyalitas diperlukan agar karyawan tersebut dapat bekerja tidak hanya untuk dirinya sendiri tetapi juga kepentingan untuk memajukan perusahaan.

Tujuan - Berdasarkan uraian latar belakang penelitian, maka tujuan dari penelitian ini yaitu untuk menganalisis Loyalitas Anak Buah Kapal (ABK) Armada Kapal Pinisi PT. Aswil Lautan Sejati.

Desain/metodologi/pendekatan - Menggunakan metode kualitatif dengan model studi fenomenologi. Informan dalam penelitian ini adalah Anak Buah Kapal (ABK) yang telah bekerja minimal selama 10 tahun (3 orang), Kapten kapal dan Pemilik kapal. Teknik pengumpulan data menggunakan wawancara, dengan teknik analisis data menggunakan reduksi data, penyajian data, kesimpulan dan verifikasi.

Hasil dan pembahasan - Berdasarkan hasil penelitian, peneliti mendapatkan kesimpulan bahwa para
\end{abstract}


ABK loyal terhadap perusahaan yang ditunjukkan melalui sikap serta perilaku mereka dalam bekerja dan terhadap rekan kerja maupun atasan meskipun tidak adanya jaminan/asuransi dalam melakukan pekerjaan mereka.

Kesimpulan - Para ABK mampu dan bertanggung jawab dalam melakukan pekerjaan berdasarkan jabatannya serta hubungan antara pemilik kapal dengan para ABK seperti tidak ada jarak. Mendukung loyalitas kompensasi bagi hasil merupakan cara terbaik yang dirasakan oleh ABK.

Implikasi Penelitian - menjadi referensi dalam strategi meningkatkan kesejahteraan karyawan, bukan aspek finansial, tapi juga non finansial seperti jaminan kesehatan, dan keselamatan.

Batasan Penelitian - penelitian saat ini terbatas pada aspek kajian loyalitas anak buah kapal PT. Aswil Lautan Sejati yang memiliki masa kerja diatas 10 tahun.

Kata Kunci : Loyalitas, Anak Buah, Kapal

\section{PENDAHULUAN}

Perusahaan memerlukan manajemen dan karyawan yang baik sebagai salah satu aset perusahaan yang memiliki peran penting dalam menjalankan kegiatan organisasi. Kesuksesan dan keberhasilan organisasi atau perusahaan dapat ditentukan oleh banyak hal, salah satu hal terpenting yang dapat menentukannya adalah sumber daya manusia (SDM) yang dimiliki. Perusahaan yang dapat mengelola dan mengoptimalkan sumber daya manusia (SDM) secara baik serta berkualitas, dipastikan akan meraih kesuksesan dan produktivitas yang tinggi.

Perusahaan tidak hanya memerlukan karyawan yang mampu, cakap dan terampil, tetapi yang terpenting mereka juga mempunyai rasa loyalitas kepada perusahaan tempatnya bekerja. Loyalitas adalah sikap yang timbul dikarenakan keinginan untuk setia baik itu pada pekerjaannya, kelompok, atasan, maupun pada perusahaannya.
Lingkungan kerja meliputi lingkungan fisik dan non fisik menjadi faktor penting yang mempengaruhi loyalitas seorang karyawan terhadap tempat kerja (Kurniawan, 2019). Sikap loyalitas diperlukan agar karyawan tersebut dapat bekerja tidak hanya untuk dirinya sendiri tetapi juga kepentingan untuk memajukan perusahaan. Menurut Sudimin (2003), loyalitas berati karyawan bersedia dengan untuk ikut serta mencpai tujuan organisasi dan menyimpan rahasia organisasi serta tidak melakukan tindakan yang merugikan organisasi selama masih berstatus sebagai karyawan. Jadi disini karyawan tidak hanya sekedar melakukan pekerjaannya yang telah diatur pada job description, namun dedikasi dari karyawan tersebut juga diperlukan sebagai bentuk usahanya dalam membantu perusahaan mencapai tujuannya. Loyalitas karyawan menjadi faktor penting bagi organisasi dalam upaya mencapai visi, misi, tgujuan serta target yang telah ditetapkan oleh perusahaan. 
PT. Aswil Lautan Sejati adalah perusahaan ekspedisi pelayaran rakyat yang berkantor di Komplek Pelabuhan Gresik, memiliki beberapa armada kapal pinisi atau disebut juga KLM (kapal layar motor) untuk menjalankan kegiatan pengiriman barang dengan tujuan di beberapa kota di Pulau Kalimantan. Segala proses kegiatan pengiriman barang tersebut dilakukan para pekerja yang disebut ABK (anak buah kapal).

Peneliti menemukan fenomena bahwa anak buah kapal (ABK) dari armada yang dimiliki PT. Aswil Lautan Sejati yaitu KLM. Sa'adah Bahari dan KLM. Aswil Bahari 1 telah bekerja selama belasan hingga puluhan tahun. Hal tersebut menunjukkan bahwa ABK betah bekerja di armada milik PT. Aswil Lautan Sejati. Long et al., 2012 mengatakan bahwa loyalitas yang tinggi menunjukkan karyawan merasa nyaman bekerja di perusahaan. Kenyamanan dalam bekerja mendorong karyawan tidak ingin meninggalkan perusahaan (betah).
Para ABK bertanggung jawab atas barang yang dikirim, menjalankan proses jasa untuk pengiriman barang dan merawat aset yang dimiliki perusahaan. Loyalitas para $\mathrm{ABK}$ yang ditunjukan dengan masa kerja mereka yang telah berjalan puluhan tahun serta tidak pernah turun kapal (tidak bekerja sebagai ABK lagi), akan menguntungkan perusahaan karena dengan adanya sifat loyal maka ABK akan memiliki semangat, tanggung jawab yang tinggi dalam melaksanakan setiap tugasnya dan selalu melindungi dan berfikir memajukan perusahaan. Namun meski telah bekerja selama puluhan tahun para ABK tidak mendapatkan kesejahteraan seperti asuransi keselamatan dan kesehatan, perjanjian ganti rugi upah/gaji apabila terjadi musibah atau terjadi suatu hal yang buruk selama melakukan pekerjaan. Karena bekerja di dunia pelayaran terdapat faktor-faktor yang tidak bisa dikendalikan oleh manusia.

Tabel 1

Data masa kerja Anak Buah Kapal (ABK) KLM. Sa'adah Bahari

\begin{tabular}{clll} 
No. & \multicolumn{1}{c}{ Nama } & \multicolumn{1}{c}{ Jabatan } & \multicolumn{1}{c}{ Masa Kerja } \\
1. & H. Suhardi & Kapten/Nahkoda & Sejak 1970 (50 Tahun) \\
2. & Egar & Kerani & Sejak 2005 (15 Tahun) \\
3. & Hasan & Juru Mudi & Sejak 2009 (11 Tahun) \\
4. & M. Darwis & Juru Mudi & Sejak 2005 (15 Tahun) \\
5. & Wahyudin & Oliman & Sejak 2009 (11 Tahun) \\
6. & Syaifudin & Mesin/Bas & Sejak 2010 (10 Tahun) \\
7. & Bas & Mesin/Bas & Sejak 1989 (31 Tahun) \\
Sumber $:$ & Data masa kerja karyawan PT. Aswil Lautan Sejati
\end{tabular}


Tabel 2

Data masa Kerja Anak Buah Kapal (ABK) KLM. Aswil Bahari 1

\begin{tabular}{llll} 
No. & \multicolumn{1}{c}{ Nama } & \multicolumn{1}{c}{ Jabatan } & \multicolumn{1}{c}{ Masa Kerja } \\
1. & H. Bahtiar & Kapten/Nahkoda & Sejak 1975 (45 Tahun) \\
2. & Ridwan & Kerani & Sejak 2000 (20 Tahun) \\
3. & Harnaeni & Juru Mudi & Sejak 1993 (27 Tahun) \\
4. & Syarifudin & Juru Mudi & Sejak 1995 (25 Tahun) \\
5. & Herul & Juru Mudi & Sejak 2015 (5 Tahun) \\
6. & Mansyur & Mesin/Bas & Sejak 2000 (20 Tahun) \\
7. & Syarifudin & Mesin/Bas & Sejak 2003 (17 Tahun) \\
8. & Asri & Oliman & Sejak 2000 (20 Tahun)
\end{tabular}

Sumber : Data masa kerja karyawan PT. Aswil Lautan Sejati

\section{TINJAUAN PUSTAKA}

\section{Loyalitas}

Loyalitas kerja merupakan kesetiaan karyawan terhadap perusahaan yang akan menimbulkan rasa tanggungjawab, sehingga karyawan akan tetap bertahan apapun kondisi perusahaan tersebut baik keadaan maju atau mundur (Stephani dan Wibawa, 2014). Menurut Oxford Dictionary loyalitas adalah kesetiaan yang ditunjukkan dengan tindakan memberi atau dukungan serta kepatuhan yang teguh dan konstan kepada seseorang atau institusi. Sedangkan menurut Hasibuan (2011), Kesetiaan dicerminkan oleh kesediaan karyawan menjaga dan membela organisasi di dalam maupun di luar pekerjaan dari dorongan orang yang tidak bertanggung jawab.

Menurut Steers dan Porter, 1983 (dalam Soegandhi et al., 2013) ada beberapa konsep loyalitas, antara lain:

1. Loyal Kepada Perusahaan
Loyalitas seperti ini menuntut karyawan untuk terus bekerja di perusahaan dalam kondisi apapun. Orang yang pindah kerja sering di anggap tidak loyal terhadap perusahaan.

2. Loyal Kepada Pekerjaan

Di sini seorang karyawan tidak loyal terhadap perusahaan, tapi loyal terhadap pekerjaan yang ia kerjakan. ia akan bekerja dengan gigih demi pekerjaannya. Karyawan seperti ini di anggap sebagai aset perusahaan yang berharga karena ia akan mengerjakan pekerjaannya dengan sebaik-baiknya.

3. Loyal Kepada Visi, Misi Dan Tujuan Perusahaan

Dalam bekerja kita harus tahu visi, misi dan tujuan perusahaan serta loyal terhadapnya. Bukan hanya job description saja. Konsep loyalitas seperti ini membutuhkan pemahaman sepenuhnya bahwa yang kita kerjakan bukan saja harus selesai dengan baik, 
tapi juga harus sejalan dengan tujuan perusahaan.

Loyalitas mempunyai manfaat untuk menumbuhkan partisipasi. Suatu partisipasi akan berhasil bila keputusan dan perencanaan dilaksanakan dengan penuh tanggung jawab. Tanggung jawab akan muncul dalam diri pekerja dari rasa mencintai, rasa memiliki, merasa dihargai dan merasa di ikut sertakan dalam proses pengambilan keputusan (Nitisemito, 2008).

Salah satu survey tentang loyalitas yang dikutip Drizin dan Schneider (dalam Runtu, 2014) menunjukkan dorongan karyawan sehingga menunjukkan loyalitas karyawan adalah Keadilan. Hal itu mencakup: adil dalam penggajian, adil dalam penilaian kinerja, dan adil dalam perumusan dan pengimplementasian kebijakan. Menurut Cunha (2002), melalui pengelolaan struktur, budaya, dan kepemimpinan dalam organisasi loyalitas dapat dibangun. Selain itu melalui hubungan yang baik antara atasan dan bawahan seperti saling percaya satu sama lain. Para bawaham perlu mengetahui bahwa atasan mereka memperlakukan mereka sebagai pribadi tidak sekedar "sumber daya" sebelum mereka termotivasi untk memberi yang terbaik bagi organisasi. (Boltax, 2011). Berdasarkan faktor-faktor yang telah diuraikan diatas dapat dilihat bahwa masingmasing faktor memiliki dampak tersendiri bagi perusahaan, sehingga yang diharapkan oleh perusahaan baru dapat terpenuhi oleh karyawan yang memiliki karakteristik seperti yang diharapkan, dan perusahaan sendiri mampu memenuhi harapan karyawannya.

Aspek-aspek loyalitas kerja yang terdapat pada individu dikemukakan oleh Siswanto (dalam Soegandhi et al., 2013), yang menitik beratkan pada pelaksanaan kerja yang dilakukan karyawan antara lain:

1. Taat pada peraturan. Kebijakan organisasi diterapkan untuk memperlancar dan mengatur jalannya pelaksanaan tugas serta dipatuhi dan dilaksanakan sebaik-baiknya. Keadaan ini akan menimbulkan kedisiplinan dalam organisasi baik intern maupun ekstern.

2. Tanggung jawab pada perusahaan. Karyawan mampu melaksanakan tugas dengan baik dan sadar akan setiap resiko pelaksanaan tugasnya akan memberikan pemahaman serta bertanggung jawab terhadap resiko atas apa yang telah dilaksanakan.

3. Kemauan untuk bekerja sama. Melakukan pekerjaan secara bersamasama akan memungkinkan organisasi dapat mencapai tujuan yang tidak mungkin dicapai oleh orang - orang secara invidual. 
4. Rasa memiliki, rasa ikut memiliki karyawan terhadap organsasi akan membuat karyawan memiliki sikap untuk ikut menjaga dan bertanggung jawab terhadap organisasi sehingga pada akhrnya akan menimbulkan loyalitas demi tercapainya tujuan organisasi.

5. Hubungan antar pribadi, karyawan yang mempunyai loyalitas kerja tinggi, mereka akan mempunyai skap fleksibel ke arah tata hubungan antar pribadi. Hubungan antar pribadi ini melputi hubungan sosial diantara karyawan, hubungan yang harmonis antara atasan dan karyawan, situasi kerja dan sugesti dari teman kerja.

6. Kesukaan terhadap pekerjaan, karyawan setiap hari datang untuk bekerjasama dengan perusahaan dalam hal ini melakukan pekerjaan yang akan dilakukan tanpa ada beban atau senang hati dengan indikator sebagai berikut (1) keunggulan karyawn dalam bekerja, (2) karyawan tidak pernah menuntut apa yang diterimanya diluar gaji pokok.

\section{Indikator Loyalitas}

Marpaung (2012) mengemukakan loyalitas adalah kepatuhan dan kesediaan karyawan yang diukur dalam empat indikator sebagai berikut:
1. Berkarir diperusahaan adalah keinginan untuk menetap di perusahaan.

2. Mengenal perusahaan yaitu memiliki pengetahuan tentang perusahaan, aktifitas perusahaan, mengenal pimpinan di divisi perkerjaan karyawan.

3. Kebanggaan sebagai bagian dari perusahaan adalah merasa menjadi bagian dari perusahaan, menjaga nama baik perusahaan, menceritakan hal-hal yang baik tentang perusahaan sebagai tempat yang tepat untuk bekerja.

4. Disiplin jam kerja adalah masuk dan keluar kerja sesuai jam kerja.

Saydam dalam Kurniawan (2019) mengemukakan indikator loyalitas kerja adalah sebagai berikut :

1. Taat terhadap peraturan seperti, mentaati segala peraturan perundangundangan dan kebijakan yang berlaku, mentaati perintah yang diberikan atasan yng berwenang dengan baik, disiplin dengam ja, kerja yang telah ditentukan.

2. Bertanggung jawab antara lain dapat menyelesaikan tugas dengn baik dan tepat waktu, mengutamakan kepentingan dinas dari kepentingan golongan, tidak pernah menyalahkan orang lain. 
3. Menyumbangkan pemikiran dan tenaga secara sukarela kepada organisasi.

4. Jujur, antara lain selalu mengerjakan tugas dengan sukarela tanpa merasa dipaksa, tidak menyalahkangunakan wewenang yang ada padanya dan melaporkan hasil pekerjaan kepda atasan apa adanya.

Gambar 1

Kerangka Berpikir

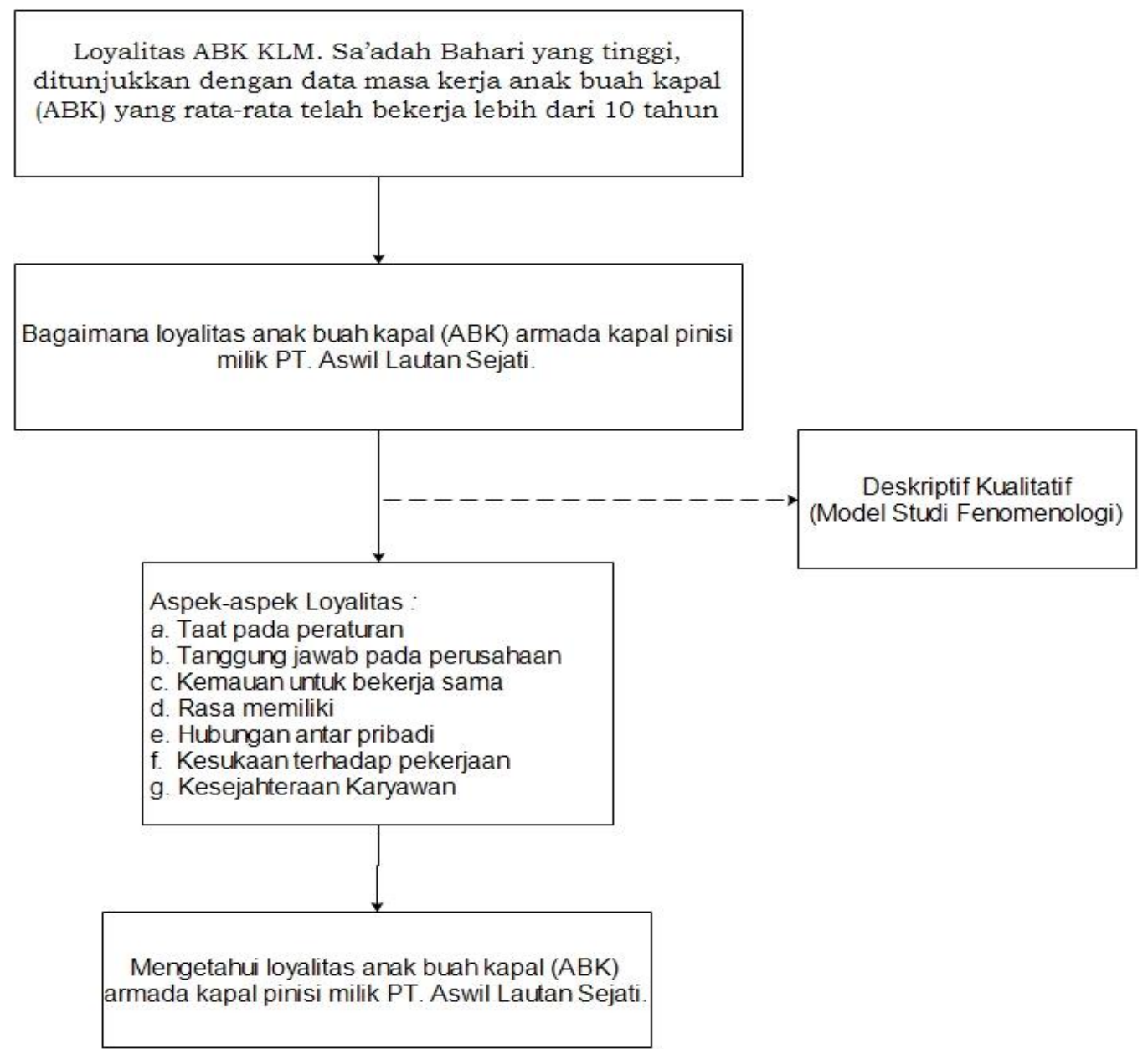

\section{METODOLOGI PENELITIAN}

Penelitian ini menggunakan pendekatan kualitatif yaitu penelitian yang menghasilkan data deskriptif berupa katakata tertulis, atau lisan dari orang- orang dan perilaku yang dapat di amati (Moleong, 2016). Penggunaan studi fenomenologi yang meneliti pengalaman manusia melalui deskripsi dari orang yang menjadi partisipan penelitian, sehingga peneliti dapat memahami pengalaman hidup partisipan. Studi fenomenologi dipilih karena penelitian ini bertujuan memahami subjek berdasarkan pengalamannya selama bekerja puluhan tahun di armada kapal pinisi. 
Anak Buah Kapal (ABK) dari armada milik PT. Aswil Lautan Sejati yaitu KLM. Sa'adah Bahari dan KLM. Aswil Bahari 1 yang berjumlah 15 orang sebagai fokus penelitian, dengan Key Informan antara lain Anak Buah Kapal (ABK) dengan masa kerja minimal 10 tahun (4 orang) dan Pemilik kapal yang sekaligus pemilik Perusahaan Ekspedisi PT. Aswil Lautan Sejati. Pengumpulan data pada penelitian menggunakan wawancara terstruktur, dengan pertanyaan yang telah di susun sebelumnya. Teknik analisis data yang di gunakan dalam penelitian ini adalah Analysis Interactive model dari Miles dan Huberman, yaitu kegiatan analisis data dengan beberapa tahapan yaitu: reduksi data, penyajian data, kesimpulan dan verifikasi (Sugiyono, 2015).

Setelah wawancara maka dilakukan Triangulasi yaitu memeriksa keabsahan data menggunakan sesuatu yang lain untuk dilakukan pengecekan atau sebagai pembanding data itu. Teknik triangulasi yang paling banyak di gunakan ialah pemeriksaan melalui sumber lainnya (Moleong, 2014). Selanjutnya dilakukan Member check yaitu proses pengecekan data yang diperoleh peneliti kepada pemberi data. Tujuan member check adalah untuk mengetahui data yang diperoleh sesuai dengan apa yang diberikan oleh pemberi data.

\section{HASIL DAN PEMBAHASAN}

Setelah melakukan wawancara terstruktur yang telah ditentukan mengenai garis besar dari fenomena loyalitas berdasarkan aspekaspek loyalitas yang dikemukakan oleh Siswanto (dalam Soegandhi et al., 2013) yaitu (1) taat pada peraturan, (2) tanggung jawab pada perusahaan/ organisasi, (3) kemauan untuk bekerja sama, (4) rasa memiliki, (5) hubungan antar pribadi, (6) kesukaan terhadap pekerjaan, serta (7) kesejahteraan dalam bekerja. Berikut interpretasi hasil penelitian dari wawancara berdasarkan aspek loyalitas tersebut:

1. Loyalitas ABK yang ditunjukan melalui perilaku dalam melakukan pekerjaan

a. Kesediakan melakukan pekerjaan diluar job description

Diketahui para ABK bertanggung jawab dan mampu melakukan pekerjaan berdasarkan jabatannya dengan baik. Bahkan dikatakan kalau para ABK tidak hanya mengerjakan job desc pada jabatannya saja, namun juga melakukan pekerjaan diluar job desc. Salah satu informan yaitu saudara Wahyudin mengatakan

\footnotetext{
"Kalau KLM semuanya itu kerjasama meskipun oliman itu mekanik tapi apapun yang harus dikerjakan ya dikerjakan. Contohnya kalau kita sedang muat nyusun barang ya bersama-sama, kalau bongkaran ya bersama-sama. Nah tapi kalau ada kerusakan dibawah ya itu tanggung jawab saya."
} 
Karyawan yang mau mengorbankan waktu yang dimiliki untuk mengerjakan tugas-tugas diluar job desc yang dimilikinya merupakan karyawan yang memiliki loyalitas yang tinggi.

b. Perilaku peduli dalam bekerja (rasa memiliki)

Masa kerja para ABK selama belasan hingga puluhan tahun akan menimbulkan rasa memiliki dan keterikatan terhadap pekerjaannya. Keterikatan tersebut dikarenakan Sense of belonging yaitu keterlibatan individu pada suatu sistem dalam lingkungannya sehingga individu tersebut merasa bahwa dirinya menjadi bagian secara keseluruhan didalam lingkungannya (Choenarom et al., 2005). Keterikatan dibuktikan dengan para ABK menganggap kapal sebagai rumah mereka sehingga apabila ada kerusakan secara otomatis mereka akan melakukan perbaikan serta merawat kapal yang merupakan aset perusahaan.

"Kapal itu ibarat seperti rumah kita, jadi kalau misal ada apa-apa ya kita peduli dengan kondisi kapal. Kepedulian itu dari lingkungan kerja kita sendiri. Kalau kita merasa nyaman otomatis kita akan peduli, tapi kalau misalkan kita enggak nyaman itu enggak bakalan peduli pasti ujung-ujungnya pindah kapal."
Selain itu sistem kekeluargaan yang diterapkan oleh Pemilik Kapal kepada para $\mathrm{ABK}$ membuat para $\mathrm{ABK}$ merasa menjadi bagian dari organisasi, mereka merasa nyaman dalam lingkungan kerjanya sehingga akan menurunkan keinginan untuk pindah ke kapal lain.

2. Terbentuknya loyalitas ABK didukung dengan hubungan yang terjalin

a. Hubungan ABK dengan rekan kerja Sasmitaningrum, 2008 mengemukakan salah satu cara yang dapat ditempuh untuk meningkatkan loyalitas kerja, yaitu hubungan yang erat antar karyawan. Hal ini disebabkan karena kesetiakawanan yang ditunjukkan oleh rekan kerja mendorong karyawan untuk tetap bersama dan sama-sama bekerja pada lingkungan kerja yang sama, sehingga rekan kerja mendorong loyalitas karyawan. Kapten dari KLM. Aswil Bahri 1 mengatakan.

"Baik semua hubungannya, sudah lama ABK tidak pernah turun kapal."

jadi para ABK tidak ingin keluar dari pekerjaannya di kapal karena selama ini mereka memiliki hubungan yang baik dengan sesama ABK atau dengan Kapten/ Nahkoda kapal. Rekan kerja yang merasa senasib di perusahaan yang saling mendukung akan mendorong karyawan untuk tidak 
keluar dari pekerjaan karena karyawan merasa memiliki ikatan emosional dengan karyawan lainnya yang lebih kuat (Andria dan Rooswanti, 2019).

b. Hubungan ABK dengan Pemilik Kapal Pak Khairul menganggap para ABK tidak hanya sebagai rekan kerja namun bahkan seperti saudara karena Pak Khairul menerapkan sistem kekeluargaan terhadap para ABK,

"Saya sama ABK alhamdulillah tidak ada jarak, saya juga sendiri prinsipnya tidak mau dibilang atasan dan bawahan. Jadi selama ini ABK tidak ada masalah dan baik saja hubungannya."

Sehingga ketika ada masalah saat bekerja Pak Khairul berdiskusi dengan para ABK untuk menyelesaikan masalah tersebut. Selain itu, Pak Khairul sering datang ke kapal untuk mengobrol dan mendengarkan keluhan-keluhan yang dirasakan para ABK sehingga ABK merasa diperhatikan, diapresiasi, dan diperlakukan dengan baik oleh pimpinan sehingga mereka tetap bertahan bekerja di kapal milik Bapak Khairul. Hal tersebut serupa dengan pernyataan yang dikemukakan oleh (Andria dan Rooswanti, 2019) seorang pimpinan yang mampu memahami kebutuhan dan keinginan karyawan menyebabkan karyawan merasa nyaman dan senang untuk tetap bekerja di perusahaan sehingga bisa meningkatkan loyalitas karyawan.

3. Kesejahteraan yang didapatkan para ABK

Kesejahteraan pekerja adalah suatu pemenuhan kebutuhan dan/atau keperluan yang bersifat jasmaniah dan rohaniah, Bentuk dari pemenuhan kebutuhan yang diberikan perusahaan adalah berupa kompensasi. Nawawi (2011) kompensasi dibagi menjadi kompensasi langsung yang berupa gaji, tunjangan dan segala jenis pembayaran kepada karyawan yang dinominalkan dan diberikan pada karyawan secara langsung. Dan Kompensasi tidak langsung yang diberikan dalam wujud bukan uang secara fisik.

a. Kompensasi langsung (gaji/upah)

Pak Kahirul sebagai pemilik kapal mengatakan

"Kita bukan pakai gaji, tapi sistem bagi hasil. Jadi kalau biasanya diluar itu bagi hasilnya dibagi 3 , kalau di saya dibagi 2."

Saudara Egar yaitu ABK dari KLM. Sa'adah Bahari mengatakan

"Alhamdulillah kalau masalah gaji mencukupi, untuk sebagian dikirim ke kampung dan kita pegang untuk sehari-hari."

Dari pembagian hasil sewa kapal, para ABK telah merasa cukup untuk memenuhi kebutuhannya dan mengirim uang untuk keluarga. 
Hasibuan (2011) kesejateraan berupa upah atau gaji yang diberikan akan bermanfaat untuk memenuhi kebutuhan karyawan beserta keluarganya. Pemberian kesejahteraan ini akan menciptakan ketenangan, semangat dalam bekerja, sikap disiplin dan sikap loyal terhadap perusahaan, sehingga turnover karyawan relatif rendah.

b. Kompensasi tidak langsung (asuransi/ jaminan)

Rasa aman dalam bekerja terjamin apabila perusahaan memberikan kesejateraan berupa kompensasi seperti asuransi/jaminan untuk keselamatan dan kesehatan para ABK. Namun sayangnya dari wawancara yang peneliti lakukan dengan para ABK, diketahui mereka tidak mendapatkan asuransi atau jaminan perihal keselamatan dan kesehatan, jaminan hari tua, pensiun dan beberapa program BPJS Ketenagakerjaan dalam melakukan pekerjaannya.

"Kalau kesejahteraan ya sedangsedang saja, menikmati apa yang ada. Kalau asuransi untuk ABK tidak ada" kata saudara Wahyudin (ABK KLM. Sa'adah Bahari). Pak Khairul sebagai pemilik kapal menambahi Kalau asuransi untuk SDM nya kalau kapal kayu itu kurang, kalau untuk kapalnya itu mungkin ada, untuk barang juga ada. Mungkin asuransi untuk SDM nya ya dari pemilik sendiri misalkan ada kecelakaan di kapal ya pemilik membantu."

\section{KESIMPULAN}

Para ABK mampu dan bertanggung jawab dalam melakukan pekerjaan berdasarkan jabatannya, bahkan mereka mau mengerjakan diluar job descnya dan membantu pekerjaan rekannya apabila diperlukan. Hal tersebut juga dipengaruhi rasa memiliki $A B K$ terhadap organisasinya yang ditunjukkan dengan mereka peduli untuk mreawat dan memperbaiki kapal. Kepedulian tersebut karena dalam PT. Aswil Lautan Sejati menggunakan sistem kekeluargaan sehingga para ABK memiliki hubungan keterikatan yang baik serta dekat yang sudah seperti saudara.

Hubungan para ABK dengan pimpinan di kapal yaitu Kapten dikatakan baik, dengan masa kerja yang telah berlangsung lama sehingga menunjukkan para ABK betah bekerja dikapal dan tidak ingin turun atau pindah ke kapal lain. Hubungan antara Pemilik kapal dengan para ABK seperti tidak ada jarak antara atasan dan bawahan, Pemilik kapal menganggap para ABK sudah seperti keluarga. Para ABK merasa diperhatikan dan diperlakukan dengan baik sehingga mereka tetap ingin bekerja di kapal.

Untuk kesejahteraan para ABK yaitu tentang upah/gaji menggunakan sistem bagi hasil untuk pendapatan para ABK telah 
cukup untuk memenuhi kebutuhan para ABK dan untuk mengirim uang bagi keluarga di kampung. Sedangkan kesejahteraan tentang keselamatan dan kesehatan dalam bekerja, perusahaan tidak memberikan jaminan asuransi kepada para ABK. Namun Pemilik kapal akan membantu untuk mengurus dan membiayai apabila terjadi musibah atau kecelakaan saat kapal sedang muat dan berlayar.

\section{IMPLIKASI PENELITIAN}

Hasil penelitian yang menunjukkan bahwa loyalitas ABK dari armada milik PT. Aswil Lautan Sejati ditunjukkan melalui masa kerja mereka yang lama yaitu belasan hingga puluhan tahun serta perilakuperilaku mereka selama melakukan pekerjaan dilapangan. Namun sayangnya mereka tidak cukup merasa aman ketika bekerja dikarenakan tidak adanya jaminan kesehatan atau keselamatan yang mereka dapatkan apabila terjadi musibah atau kecelakaan saat melakukan pekerjaannya.

Diharapkan hasil dari dilakukannya penelitian ini dapat digunakan oleh pemilik kapal untuk lebih memperhatikan aspek kesejahteraan non financial berupa jaminan kesehatan para sumber daya manusianya, agar mereka semakin bersemangat dalam bekerja dan dapat mewujudkan tujuan perusahaan lebih cepat. Selain itu untuk penelitian selanjutnya, diharapkan penelitian ini bisa dijadikan pedoman untuk melakukan penelitian dengan menambahkan variabel lain seperti besaran kompensasi atau K3 dalam bekerja yang mempengaruhi loyalitas karyawan dengan objek dan teknik penulisan yang berbeda.

\section{ACKNOWLEDGEMENT}

Penulis mengucapkan terimakasih kepada Bapak Khairul yang merupakan Pemilik kapal dan pemilik Ekspedisi Pelayaran Rakyat serta Kapten dan para ABK dari armada milik PT. Aswil Lautan Sejati yang membantu dalam memberikan data dan informasi untuk digunakan dalam penelitian ini sehingga penelitian ini dapat selesai. Diharapkan penelitian ini dapat menambah khasanah ilmu pengetahuan dalam bidang Manajemen Sumber Daya Manusia.

\section{DAFTAR PUSTAKA}

Andria, Jessica dan Rooswanti Putri. 2019. Mengungkap Loyalitas Karyawan Dengan Gaji Di Bawah Standar Minimum. AGORA Vol. 7, No. 1

Boltax, Jason. 2011. Love 'Em or Lose 'Em: Retaining Talented Employees. CPA Practice Management Forum, 19-22 
Choenarom, C., Williams, R. A. dan Hagerty, B. M. 2005. The role of sense of belonging and social support on stress and depression in individuals with depression. Archives of psychiatric nursing, 19, 18-29

Cunha, Miquel Pinae. 2002. "The Best Place to Be": Managing Control and Employee Loyalty in a Knowledge Intensive Company. The Journal of Applied Behavioral Science, Vol. 8 (2): 481 495

Hasibuan, M.S.P., 2011, Manajemen sumber daya manusia (Edisi revisi), Bumi Aksara, Jakarta

Kurniawan, I.S. 2019. "Faktor-Faktor Yang Mempengaruhi Loyalitas Karyawan”. Kinerja, 16(1) 2019

Long, C.S., Ajagbe, M.A., Nor, K,M. dan Suleiman, E.S. (2012). The approaches to increase employees' loyalty: A review on employees' turnover models. Australian Journal of Basic and Applied Sciences, 6(10), 282-29

Marpaung, R, 2012, Kinerja dan Loyalitas Karyawan, Gramedia Pustaka Utama, Jakarta

Moleong, Lexy. J, 2016, Metodologi Penelitian Kualitatif Edisi Revisi, PT. Remaja Rosdakarya, Bandung

Nawawi, Hadari, 2011, Manajemen Sumber Daya Manusia : Untuk Bisnis yang Kompetitif, Gajahmada University Press, Yogyakarta

Nitisemito, Alex S, 2008, Manajemen Personalia (Manajemen Sumber Daya. Manusia), Ghalia Indonesia, Jakarta

Runtu, Julius, 2014, Indikator Loyalitas Karyawan, Jakarta

Sasmitaningrum. 2008, Manajemen Sumber Daya Manusia, Ghalia Indonesia, Bogor

Soegandhi, Vannecia Marchelle., Drs. Eddy M. Sutanto, M.Sc dan Roy Setiawan, S.Kom.,MM.,MSM. 2013. Pengaruh Kepuasan Kerja dan Loyalitas Kerja Terhadap Organizational Citizenship Behavior pada Karyawan PT. Surya Timur Sakti Jatim. AGORA Vol. 1, No. 1

Stephani, L. A., dan Wibawa, I. M. A. 2014. Pengaruh Kompensasi dan Lingkungan Kerja pada Loyalitas Karyawan Berdasarkan Jenis Kelamin, 1, 3078-3095

Sudimin. 2003. Whistleblowing: Dilema Loyalitas dan Tanggung Jawab Publik. Jurnal Manajemen dan Usahawan, Vol. 12 (No. 11), 3-8,

Sugiyono. 2015. Metode Penelitian Pendidikan (Pendekatan Kuntitatif, Kualitatif, Dan R\&D). Bandung. Alfabet. 